\title{
EL ALCANCE DEL INCISO "B)" DEL ARTÍCULO 8 DE LA LEY DE MARCAS NICARAGÜENSE: DE LOS ÁNGULOS DEL PRINCIPIO DE ESPECIALIDAD A LOS SUPUESTOS DE CONFUSIÓN-ASOCIACIÓN Y MARCAS INADMISIBLES ${ }^{175}$
}

\author{
Julia Marcia Peña Pérez \\ Labora en la Corporación Agrícola de Nicaragua
}

\section{Resumen}

En el artículo se puede encontrar un análisis sobre el alcance del derecho titular de una marca; siendo necesario para el estudio del tema la utilización del principio de especialidad, los supuestos de riesgo de confusión, asociación y marcas renombradas o notorias. Para abordar el estudio se recurre, además, a la legislación nacional como es la Ley de Marcas y su Reglamento que es precisamente donde se genera la polémica objeto de nuestro estudio, dado que en los artículos 8 inciso b) y 26 inciso e) de la Ley y el artículo 12 del Reglamento de la Ley consagran dos formas distintas de aplicar y entender el principio de especialidad, lo cual ha ocasionado confusión en nuestro foro.

Por un lado, los artículos 8 inciso b) y 26 inciso e) de la Ley regulan, desde nuestro punto de vista de forma correcta, los derechos exclusivos del titular de una marca, sin que éstos se vean limitados o afectados ante la pretensión de que un tercero quiera inscribir posteriormente en el Registro signos idénticos o similares dentro de la misma clase o no para un producto, servicio o mercancía diferente a la ya inscrito. Contario sensu a lo establecido en la Ley, el artículo 12 del Reglamento, restringe o limita el derecho marcario en el sentido de que si la marca que se quiere inscribir es idéntica o similar a la ya inscrita procede si es con un producto diferente aunque sea dentro de la misma clase, de ahí se analiza entonces la jerarquía las normas, la protección del titular de la marca y la aplicación de la posición cimentada de la doctrina.

Palabras clave: principio de especialidad/ marca/ confusión/ asociación/ signos

\section{Introducción}

Corría el año dos mil cinco cuando en el Registro de la Propiedad Intelectual (RPI) de Managua se presentó oposición a la inscripción de una marca por entender el titular, que previamente había inscrito productos para una clase en particular, que la inscripción pretendida por

$175 \mathrm{El}$ presente artículo es el resultado del trabajo de investigación realizado para obtener el título de Máster en Derecho de Empresas con Especialización en Asesoría Jurídica; el cual además de ser evaluado por un Tribunal integrado por tres académicos; posteriormente, fue arbitrado por una Comisión a efectos de seleccionar a los participantes del I Encuentro de Investigación de Postgrado de la Universidad Centroamericana, 2009. 
un tercero laceraba su derecho adquirido en la medida que generaría un alto riesgo de asociación o confusión sobre sus productos en el mercado, entretanto el tercero sostiene que se propone inscribir una marca para un producto que no tiene titular, y en consecuencia no está legitimado para oponerse quien no tiene la titularidad del producto, pues su derecho solo alcanza para las marcas sobre los productos que ya tiene inscritos y no para otros expectantes o potenciales. La resolución final de este caso aún pende, tras la interposición de recursos. Las posiciones decisorias han pendulado, las partes han basado su estrategia defensiva sobre idéntico elemento toral: El consabido principio de especialidad de alto relieve en materia marcaria, aunque, por supuesto, vislumbrado desde ángulos diversos.

Pero la referencia acabada de exponer, sobre un caso real, más allá de la anécdota y su final decisión -que repetimos pende- es traída a colación como pivote e incentivo de este modesto empeño académico. Desentrañar desde la ciencia del Derecho, y en particular desde la disciplina del Derecho Marcario, el alcance del inciso b) del artículo 8 de la Ley No. $380^{176}$, piedra angular de todo el debate legal, es el cometido central de este trabajo.

Constituye un hallazgo y motivo de reflexión, desde el punto de vista jurídico, constatar que las partes, en el proceso de referencia, han esgrimido el mismo principio de especialidad para sostener posiciones jurídicas diametralmente opuestas. Luego de releer y aprehender el precepto en cuestión se colige, de forma muy elemental, que optar por una posición fundamentada en dogmática jurídica no es tarea fácil, o por lo menos no es cuestión ligera. Cualquier posición que se adopte supondrá introducirse, para desentrañar, alambicadas instituciones de Derecho Marcario que constituirán los ingredientes o partes a estudiar en armonía y concatenados, para obtener un resultado; tal cual será, el sostener con soporte dogmático científico un criterio interpretativo del precepto en cuestión. Lo cual traspolado a la teoría de interpretación de las leyes no será más que un ensayo de interpretación literal y doctrinal de la norma.

176 Reglamento de la Ley de Marcas y Otros Signos Distintivos, Decreto No. 83-2001, publicado en La Gaceta, Diario Oficial No. 183, del 27 de septiembre del 2001. Artículo 12. Propiedad de una Marca. La propiedad de una marca y el derecho a su uso exclusivo solo se adquiere con relación a los productos, mercancías o servicios para los que se hubiere solicitado y que estén comprendidos en una misma clase, sin perjuicio de lo establecido en el Arto. 8 de la Ley. 
Revista de Derecho

\section{La polémica del inciso b) del artículo 8: Presentación y ejes del debate}

Como ha quedado dicho en la parte introductoria de este trabajo, ha sido constatada en la práctica jurídica nicaragüense interpretaciones encontradas en la aplicación del artículo 8 inciso b) de la Ley de Marcas y el artículo 12 del Reglamento de esta Ley ${ }^{177}$. El primero regula las marcas inadmisibles por derechos de terceros y el segundo define la propiedad de una marca. La contradicción constatada se estructura sobre la base de que el artículo 12 del Reglamento, pareciera que pone límites o circunscribe el derecho marcario para los productos, servicios, o mercancías que tiene el titular inscrito en una misma clase, generando interpretaciones de que al tenor de este precepto podrán inscribirse signos idénticos o similares a los de un titular anterior dentro de la propia clase siempre y cuando ese titular no tenga inscrito esos productos aún dentro de su misma clase, y si esto es posible, pues también entonces con mayor razón, y conforme esta tesis interpretativa - y que desde ya anotamos que no compartimos - se podrán inscribir signos idénticos o similares en otra clase cuando el titular del signo no los haya inscrito en aquella otra clase. Ante este precepto del Reglamento, se erigen los artículos 8 inciso b) y 26 ambos de la Ley de Marcas y sus reformas ${ }^{178}$, que refrendan los derechos de exclusiva de un titular, sin limitarlos a clase alguna, permitiendo que el titular de la marca oponga frente a terceros cualquier inscripción siempre que le cause riesgo de confusión o asociación.

Lo cierto es que el titular de la marca inscrita y que se opone a que un tercero inscriba como suya la marca de aquel, aunque para producto distinto, alega a su favor el citado artículo 8 inciso b), y el artículo 26

177 La Ley 380, Ley de Marcas y Otros Signos Distintivos fue reformada por la Ley de Reformas y Adiciones a la Ley No. 380, Ley de Marcas y Otros Sigilos Distintivos, Ley 580, publicada en La Gaceta, Diario Oficial No. 60, del 24 de marzo del 2006. Arto. 4. Se reforma el primer párrafo del artículo 26, el que se leerá así: "Artículo 26. Derechos Exclusivos. El titular de una marca registrada gozará del derecho exclusivo de impedir que terceros, sin su consentimiento, utilicen en el curso de sus operaciones comerciales signos idénticos o similares, incluyendo indicaciones geográficas, para mercancías o servicios relacionados con las mercancías y servicios protegidos por una marca registrada, cuando ese uso dé lugar a probabilidad de confusión. En el caso del uso de un signo idéntico, incluyendo una indicación geográfica, para mercancías o servicios idénticos, se presumirá la probabilidad de confusión. Gozará del derecho de ejercer ante los órganos jurisdiccionales las acciones y medidas que correspondan contra quien infrinja su derecho. El titular de una marca registrada podrá impedir a cualquier tercero realizar los siguientes actos:"

178 El arto. 26 fue de los preceptos reformados por la Ley No. 580, Ley de Reformas y Adiciones a la Ley No. 380, cuyos datos han sido citados, concretamente fue reformado por el arto. 4 de la citada Ley No. 580. 
ambos de la Ley de Marcas ${ }^{179}$; por su parte, el tercero que pretende la inscripción de la marca idéntica a la del anterior titular, utiliza a su favor el artículo 12 del Reglamento de la Ley, en el entendido de que ese artículo acota el derecho del titular de la marca anterior únicamente a los productos o servicios que para una clase tiene inscrito el titular, abriendo así el espacio para que otros inscriban la misma marca para productos diferentes. Qué criterio debe prevalecer conforme la interpretación dogmática de la norma es justo el cometido del presente empeño investigativo.

El artículo 8 de la Ley de Marcas queda regulado bajo la sistemática de "marcas inadmisibles por derechos de terceros", entendiendo como tales pretendidos derechos marcarios, que por protección a derechos de terceros no son admisibles de inscripción, es decir quedará denegada la inscripción del derecho que se invoca por concurrir alguna causal que el ordenamiento positivo estima como excluyente para el derecho que se pretende inscribir. En este espíritu el artículo 8 ordena en sus incisos, una amplia gama de supuestos, conforme los cuales no serán admitidas las inscripciones de marcas en las que concurran algunas de las circunstancias que el citado artículo diseña.

De esa amplia gama de supuestos extraemos para análisis y estudio uno en particular y es el referido a la denegación de inscripción de marcas por vulnerar o dañar derechos de terceros, cuando se pretende inscribir un signo idéntico o similar a otro previamente inscrito y ello genera un riesgo de confusión o asociación, categoría que quedó plasmada en el inciso b) del citado artículo y que constituye el centro de reflexión legal en esta obra.

Reza en el inciso b) del artículo 8 de la Ley que una marca será inadmisible cuando "El signo es idéntico o similar a una marca registrada o en trámite de registro en el país por un tercero desde una fecha anterior, que distingue los mismos o diferentes productos o servicios, si su uso pudiera causar un riesgo de confusión o de asociación con esa marca”.

Conforme la literalidad de esta norma serán denegadas las inscripciones de marcas cuando se pretenda la inscripción de un signo que sea bien idéntico o bien similar al que ya otro, de antemano, tiene inscrito o en trámite de inscripción, siempre y cuando, y así lo establece como condicionante el precepto, se causare un riesgo de confusión o asociación

179 LOBATO, Manuel, Comentarios a la Ley 17/2001, de Marcas, editorial Civitas, Madrid, 2002. 


\section{Revista de Derecho}

con la marca primeramente inscrita y reconocida, es decir se narra una relación causa efecto: La existencia del signo similar o idéntico a otro (causa) origina el riesgo de asociación o confusión (efecto). Pero el inciso en comentario establece un elemento neurálgico que complementa lo hasta aquí dicho y es que diseña la similitud o identidad del signo en función de distinguir los mismos o diferentes productos o servicios.

En el hilo de esta interpretación literal el legislador lo que ha querido tutelar son los derechos del titular de una marca contra terceros, impidiendo que se inscriba un signo que por ser idéntico o similar al de un titular genere una confusión que a la postre lacera su derecho de propiedad intelectual que no ha sido más que el reflejo de su esfuerzo por distinguir sus productos en el mercado, y de lo cual indebidamente no debe aprovecharse quien no generó el esfuerzo de distinción. Conforme esta posición, lo que salvaguarda el inciso en estudio es el derecho de los titulares de una marca que para ser entendido en toda su magnitud necesariamente habrá que remitirse aquella parte del cuerpo normativo que postula y consagra el derecho de propiedad sobre las marcas que en la Ley sería el arto. 26, titulado derechos exclusivos, y aunque contradictoriamente, pero por legalidad, necesariamente ha de ser traído a colación, el arto. 12 del Reglamento titulado "Propiedad de una marca”.

El punto central en este tema estará en determinar cuál es el alcance del derecho del titular de una marca, lo cual constituirá a su vez el límite para que los terceros que quieran hacer uso de ella se encuentren impedidos.

Para la adopción de una posición legal sobre esta polémica, a sustentarse con algún nivel de cientificidad jurídica, deberán ser estudiadas y articuladas un grupo de categorías del Derecho Marcario, como lo son el principio de especialidad, los riesgos de confusión o asociación, y las marcas renombradas o notorias, éstas constituirán el eje en torno al cual debe girar todo el debate alrededor del tema planteado.

\section{El principio de especialidad en materia marcaria}

\section{Conceptualización}

A fin de entrar en contacto con el principio de especialidad, conocerlo un poco más y entenderlo mejor, a la luz del sentido de su incorporación en nuestro ordenamiento jurídico, plasmaremos algunas definiciones 


\section{Revista de Derecho}

realizadas por estudiosos del Derecho de Marcas, para luego adoptar una consideración propia.

Según el tratadista Manuel Lobato, respecto al principio de especialidad y su aplicación: "Al abordar la semejanza entre dos marcas es imprescindible tener en cuenta el principio de especialidad. El principio de especialidad permite la convivencia de signos idénticos o similares en cuanto a sus elementos fonéticos, gráficos o conceptuales si los productos o servicios a los que se refieren dichos signos son lo suficientemente distintos como para que no se suscite el riesgo de confusión respecto del origen empresarial." ${ }^{180}$

Por su parte Riofrío Martínez-Villalba, igualmente relacionando el principio de especialidad respecto al riesgo de confusión, dice que: "Por el principio de la especialidad, cuando se solicita el registro de dos signos iguales en dos clases distintas, no suele haber riesgo de confusión. No obstante, de existir tal riesgo, entonces la protección que se confiere a la marca registrada traspasa los límites de la clase donde se registró, y su titular puede oponerse o impugnar el registro del signo que causa la confusión. Por el principio de especialidad cada marca se relaciona con un producto; por el de no confusión se determina el grado de protección efectiva de la marca." ${ }^{181}$

$\mathrm{Al}$ respecto dicen Martínez Medrano/Soucasse que "Una marca protege a una designación, dibujo, forma, etc., pero no para todos los productos o servicios posibles, sino solamente para los productos para los cuales se ha solicitado".

De las definiciones anteriores puede desprenderse, como elemento común denominador, que el principio de especialidad se ha articulado en materia marcaria para postular el derecho exclusivo que corresponde al titular de una marca, pues no se trata de fundamentar una oposición al registro de otras marcas similares, bajo el fundamento de la especialidad, si ellas no conllevan a confusión o asociación; por este principio, se permite la convivencia de signos idénticos o similares si hay una clara

180 RIOFRÍO MARTÍNEZ-VILLALBA, Juan Carlos, Principios del Derecho de Marcas en la Comunidad Europea, Artículos Doctrinales: Derecho Mercantil [en línea]. Disponible en: Noticias Jurídicas.

$181 \mathrm{Al}$ respecto de cómo queda regulado este principio en ambas legislaciones Vid. Infra II. 3. 


\section{Revista de ODerecho}

diferencia de los productos o servicios que distinguen y no hay atisbos de crear una distorsión de la realidad en el mercado, distorsión en la mente del consumidor que lo lleve a engaño; nótese que se ha hablado de productos y servicios y no de clases, pues no es la clase la que determina la semejanza sino que los productos o servicios en relación a la marca.

Ensayando una definición propia sostenemos, que el principio en comentario, es expresión y enarbola los derechos que el titular tiene sobre su marca que son especiales en tanto quedan identificados los bienes, productos o servicios sobre los que recae, y justamente ese criterio de especialidad que califica de singular y único los derechos sobre marcas - y por ello exclusivos - es lo que refrenda al titular de la marca para erigirse frente a cualquier situación que dañe o coloque en riesgo de dañar la singularidad y exclusividad, en síntesis, la especialidad de su derecho.

Quedando dicho, como ha sido, que el principio de especialidad es irradiación del derecho de exclusiva, habrá que agregar que éste alcanza especial relieve y constatación práctica, ante los supuestos de confusión o asociación de marcas en el mercado, en cuyo caso suele enarbolarse en función proteccionista - defensiva, por lo tanto es un principio que detona ante los riesgos de confusión o asociación y ha sido con esta visión que ha quedado plasmado tanto en la legislación española como en la nuestra ${ }^{182}$.

\section{Los contornos del principio de especialidad}

Una vez anotado que el principio de especialidad se postula en función de proteger al titular de la marca en su derecho exclusivo, esto a su vez indicará los límites y contornos del propio principio, es decir los terceros han de abstenerse y respetar el derecho del titular, bien porque la marca ha sido inscrita anteriormente, o bien para evitar generar un riesgo de confusión o asociación, o bien porque la marca ha adquirido tal renombre en el mercado que el derecho de ese titular debe ser protegido. No es posible circunscribir el principio de especialidad al mero hecho que protege al titular respecto a la clase para la cual se encuentra literalmente extendido el registro, sino que tiene un alcance más amplio que viene dado por los riesgos de confusión o asociación.

182 MARTÍNEZ MEDRANO, Gabriel/SOUCASSE, Gabriela, Derecho de Marcas, ed. La Roca, Buenos Aires, 2000, pág. 55 . 


\section{Revista de Derecho}

El principio de especialidad no puede ser visto de forma restrictiva circunscrito como inherente a la clase o producto, a lo que va unido y es inherente es a la protección del derecho del titular de la marca, será especial en la medida que la titularidad de la marca otorga un derecho de exclusiva a su titular y conforme ese principio el titular defenderá erga omnes su derecho, sin que quepa invocar que el principio de especialidad restringe el derecho del titular a la manera de que no puede ser articulado para defenderse cuando un tercero pretende inscribir como suya un signo idéntico o similar ya inscrito, en el entendido de que la especialidad se circunscribe únicamente al producto registrado o a la clase para la cual fue otorgado el registro; y por tanto el titular debe tolerar que otro inscriba un signo suyo ya inscrito, aunque para otro producto. Se trata entonces de un principio que debe ser redimensionado conforme a la naturaleza del derecho marcario que consagra por sobre todo la protección al titular activo, es decir que usa en el comercio la marca y en esa medida ha de ser visto y entendido.

De lo expuesto en el párrafo anterior puede constatarse que existe una interpretación amplia y una interpretación restringida del principio de especialidad. Conforme la visión restringida el principio de especialidad no tiene más contornos que los que origina el derecho concreto que recae sobre el producto, servicio o mercancía que se tiene inscrito. La especialidad se articula o entiende como una relación cuasi - física entre el derecho y el bien sobre el que recae. Visto así el titular no tiene más que ejercitar los derechos que dimanan de la inscripción misma, su derecho es visualizado de forma tan especial, que peca por restringida, desvirtuando así la socialización e interrelación que generan las marcas en el mercado.

Por su parte la interpretación amplia y redimensionada del principio de especialidad fija que éste tendrá por contornos los mismos que tenga la protección del derecho marcario, más allá de la visión segmentada o parcelaría del bien, producto o servicio sobre el que recae; posición que suscribimos.

En nuestra percepción el principio de especialidad debe ser observado también desde el punto de vista del público a quien va dirigido el producto o servicio ofrecido a través de una marca; porque si bien es cierto que la marca identifica el origen empresarial de los bienes, esta función no está dada en abstracto, sino que tiene una aplicación real y práctica que es la actividad comercial en donde el consumidor va a seleccionar de una 


\section{Revista de ODerecho}

gama de posibilidades las que satisfagan sus necesidades; y el empresario luchará denodadamente por obtener la preferencia de la mayor parte de esos consumidores que le redundan un beneficio económico; algunos empresarios lo harán con los métodos y recursos legales que están al alcance de todos, otros lo harán tratando de aprovecharse del esfuerzo ajeno; es aquí donde intervienen todos los recursos que la ley prevé para estas situaciones y paralelamente en el camino se va creando la práctica e interpretación de esa legislación que circunscribe los derechos de cada uno de los actores que se desenvuelven en el mercado, entiéndase aquí especialidad de la marca.

En este afán del empresario de posicionarse en un mercado ingente y de llegar a más personas que le redunden en beneficios económicos es que los ofertantes de productos y servicios invierten tanto esfuerzo físico como económico llegando a crear marcas conocidas en un sector mayoritario del mercado; las que son conocidas como marcas notorias o renombradas, dichas marcas rebasan los criterios de defensa de una marca y el principio de especialidad concebido en sentido restringido; esta categoría de marcas serán presentadas en páginas posteriores del presente trabajo de investigación.

\section{3. ¿Marcas notorias y renombradas excepciones al principio de especialidad?}

Con el devenir de su actividad y su esfuerzo, el empresario imprime en sus productos o servicios cualidades y calidades que los haga favoritos en las preferencias del público a quien van dirigidos; los hace especiales y los distingue del resto de su misma especie; esa preferencia y el grado de conocimiento que una marca tiene entre los consumidores es lo que le caracteriza como notoria o renombrada.

En palabras sencillas y resumidas las marcas notorias son las que son ampliamente conocidas por el sector al que van dirigidos los productos o servicios protegidos por ellas y las marcas renombradas son las conocidas por la generalidad de las personas aún aquéllas a quienes no están dirigidos o no consumen los productos o servicios identificados por las marcas renombradas.

Pareciera que la condición para la protección, bajo esta categoría de marcas notorias o renombradas es la situación de registro; aunque la marca no esté registrada para todas las clases y productos, sino 
para una clase o productos en particular, cuando alcanza el grado de renombre o notoriedad, su protección se hace extensiva para todas las clases; sin embargo, tanto la ley nicaragüense como la española prevé la protección a marcas no registradas, pues se puede suscitar la situación que una marca esté registrada en un país y sea ya conocida con grado de notoriedad o renombre en otro país aún cuando no haya sido registrada en este último. Al respecto dice la ley de marcas nicaragüense sobre signos notorios; artículo 81. (...) “En ningún caso será condición para reconocer la notoriedad de un signo distintivo: 1) Que esté registrado o en trámite de registro en el país extranjero."

Es mantenido por un sector de la doctrina, que las marcas notorias o renombradas son una excepción al principio de especialidad, pues conciben que la especialidad de la marca está dada en función de la clase; contemplando este principio como principio de especialidad o noción de clasificación de marcas; al respecto dicen los autores Martínez Medrano/ Soucasse, "Una marca protege a una designación, dibujo, forma, etc., pero no para todos los productos o servicios posibles, sino solamente para los productos para los cuales se ha solicitado"183. Y continúan diciendo estos autores, citando la Revista "Patentes y Marcas", 1941, pag 340, "Porque la marca solo protege a los artículos para los cuales ha sido registrada y nada más. De aquí que esa misma marca pueda ser registrada por cualquier otra persona para distinguir productos de otra clase, siempre que no hubiese adquirido notorio crédito o notoriedad suficiente que impida dicho registro".

La existencia de este tipo de marcas - notorias o renombradas - en el mercado ha venido constituyendo una limitante para que los terceros puedan inscribir marcas que colisionen con éstas, aunque se trate de inscripciones pretendidas para otras clases u otros productos que no han sido previamente registrados, pero la notoriedad o renombre excluyen el pretendido derecho de inscripción por los terceros. Es así que se ha sostenido que esto constituye una excepción al principio de especialidad en el entendido de que el derecho de exclusiva y principio de especialidad queda circunscrito para los productos, servicios, o mercancías que se tengan registrados, por lo tanto sólo por vía de excepción podrá permitirse extrapolarse a otra clase o productos. En nuestra percepción esta posición es consecuente con lo que hemos denominado en este trabajo visión restrictiva o restringida del principio de especialidad ${ }^{184}$.

183 Vid. Supra II.2. "Contornos al principio de especialidad"

$184 \mathrm{Al}$ respecto Otamendi en su obra Derecho de Marcas, 4ta edición, ed. Lexis Nexis, 2002, pág. 172, 
Contrario a la anterior posición entendemos que el principio de especialidad encuentra su máxima expresión en las marcas notorias y renombradas, extendiendo la protección de éstas a otras clases en las cuales no había sido registrada la marca, cuanto más aún, deben protegerse y defenderse estas marcas de las pretensiones de terceros dentro de la misma clase, puesto que el riesgo de confusión es mayor y este puede estar dado porque el pretensor desea registrar una marca similar para productos idénticos o porque pretende registrar una marca idéntica para productos similares dentro de la misma clase o en otras clases con las que hay una vinculación notoria ${ }^{185}$ de los productos por la función que desempeñan. Sobre esta materia conoce la doctrina el caso Baron para proteger cigarros clase 34 y Baron para proteger fósforos clase 34. En algunos sectores del comercio, existen productos que son complementarios unos de otros; al registrarse la marca Baron para fósforos cuando ya existe una marca registrada Baron para cigarros, se incurre en riesgo de asociación puesto que el consumidor puede considerar que los productos proceden del mismo empresario, o bien que el empresario de los cigarros, encomendó al de fósforos la elaboración de este producto con una función de publicidad.

El principio de especialidad en materia marcaria debe ser concebido en atención o en función de proteger la creación empresarial y el esfuerzo del empresario por distinguir sus productos en el mercado, ese ha de ser el real fundamento de la especialidad, que termina obviamente proyectándose en un producto, mercancía o servicio, pero se trata de un concepto supra o una visión supra al producto, mercancía o servicio concreto. Quiere esto decir que siempre que se ponga en riesgo la protección que merece el empresario por la identidad y singularidad de creaciones, indicará igualmente un riesgo o quiebre al principio de especialidad.

No admitir u oponerse a la inscripción de una marca, por la existencia de una anterior que resulte ser notoria o renombrada, lejos de constituir una excepción al principio de especialidad es una confirmación a este principio concebido en sentido amplio o como se ha dicho en el párrafo anterior concebido con una visión supra: Si sostenemos, como lo hacemos, que el

dice: que también se puede producir confusión entre marcas que distinguen artículos distintos en una misma clase. (...) En las oposiciones en una misma clase se ha admitido la posibilidad de confusión cuando existe entre los productos que amparan las marcas una "marcada similitud", una "indudable proximidad", una afinidad" o bien son "semejantes" o "notoriamente vinculados por su función". En nota al pie cita, el tabaco y los artículos para fumador, cigarrillos, etc.

185 Ley 17/2001, de 7 de diciembre 2001, BOE no. 294, del 8 de diciembre del 2001. 
principio de especialidad se articula en función de proteger el esfuerzo que realiza el empresario por distinguir sus productos, mercancías o servicios en el mercado, entonces la prohibición de inscribir marcas semejantes a marcas notorias o renombradas constituyen expresión de éste principio, en la medida que se protege la magnitud de un esfuerzo empresarial a la altura de alcanzar renombre y notoriedad, amén de su inscripción.

\section{El marco legal de la especialidad en la legislación nicaragüense}

Si hemos venido sosteniendo que el principio de especialidad es una expresión de los derechos de exclusiva que se otorgan al titular de una marca, entonces su consagración en el derecho positivo habrá de encontrarse bajo la sistemática de derechos exclusivos, que en nuestro caso queda consagrado en el artículo 26, de la Ley, y complementado con el artículo 8 del propio cuerpo legal.

Los artículos citados 8 y 26 constituyen expresión del principio de especialidad en su sentido amplio. Estos artículos refrendan los derechos que tiene el titular sobre sus marcas. Circunscrito al tema objeto de este trabajo, las voces del artículo 8 b), y 26 e), enuncian que el titular de una marca registrada gozará del derecho exclusivo de impedir que tercero sin su consentimiento, utilice en el curso de sus operaciones comerciales signos idénticos o similares en los siguientes casos: inciso e): "Usar en el comercio un signo idéntico o similar a la marca respecto de cualesquiera productos o servicios cuando tal uso pudiese causar confusión o un riesgo de asociación con el titular del registro, quedando entendido que tratándose del uso de un signo idéntico para productos o servicios idénticos se presumirá que existe probabilidad de confusión." En ninguno de estos artículo se hace excepciones respecto de los bienes; vemos aquí que la especialidad está dada respecto del titular, la marca es especialmente concedida para su uso exclusivo; en el entendido que dicho uso exclusivo está dado en virtud de la esencia y función de la marca los cuales trascienden la titularidad, pues si bien su función principal es "marcar", identificar, imprimir una característica que identifique o diferencie los productos y servicios de un empresario con respecto de otros empresarios, así mismo tiene o cumple funciones respecto de los usuarios, derivándose de ellas funciones secundarias que algunos usuarios de los productos o servicios atribuyen a los signos distintivos; así, un estilo de vida, una filosofía; como podemos apreciar con la marca eslogan: "just do it" que en su traducción al castellano es el equivalente de hazlo de Niké, utilizado para artículos deportivos. 
En contraste con esta regulación en el cuerpo de Ley encontramos el artículo 12 de su Reglamento, que ha sido el precepto que se utiliza como pivote para enarbolar posiciones encontradas y contradictorias sobre el principio de especialidad. En nuestro parecer, y ya anticipamos conclusiones, este artículo 12 tiene una redacción patológica causante de las posiciones antagónicas que se han suscitado en la práctica sobre el alcance de los derechos de exclusiva del titular de la marca. Según la voz de este artículo "la propiedad y el derecho al uso exclusivo de una marca solo se adquiere con relación a los productos, mercancías o servicios para los que se hubiere solicitado y que estén comprendidos en una misma clase, sin perjuicio de lo establecido en el Arto. 8 de la Ley".

En nuestra opinión el principio de especialidad recogido en los artículos citados, 8 y 26, ambos de la Ley, han de primar en su aplicación, los que están conceptuados como un argumento a esgrimir por el titular para impedir a otros registrar o usar signos idénticos o similares a los de él en el mercado y el propósito fundamental es evitar la confusión o asociación que se puede suscitar en ocasión de dos situaciones: similitud o identidad de los signos y similitud o identidad en los productos. Sin embargo, debido a como quedó dicho ut supra, el mismo principio puede ser invocado tanto por el titular como por el aspirante a obtener un derecho posterior; según la visión amplia o restrictiva que se tenga del principio, pero lo cierto es que el fin de este principio es el de evitar la confusión en defensa tanto del titular del bien (signo distintivo) como del público consumidor; entonces uno de los fines de la especialidad es evitar la confusión del consumidor a la par de proteger el derecho del titular de una marca anterior que presente similitud o identidad.

En el propósito de conocer el estado de nuestra legislación en el tema respecto de otra, unánimemente admitida como una legislación de avanzada, repasamos la Ley de Marcas Española, Ley No. 17/2001, de 7 de Diciembre del $2001^{186}$, concluyendo que la nuestra al igual que aquella recoge el principio de especialidad, sólo que la española únicamente en el sentido amplio del principio, sin la patología que en nuestro caso introduce el artículo 12 del Reglamento de la Ley. En la Ley española el principio de especialidad se recoge en sus artículos 6 literal b y 8 literal 1 . 
Nótese que en el contexto jurídico español el principio de especialidad aparece recogido y vinculado dentro de las marcas y nombres comerciales notorios y renombrados registrados; lo cual es coincidente con la opinión que expresamos sobre las marcas notorias y renombradas ${ }^{187}$, confirmando que las marcas notorias y renombradas son una expresión y ratificación de este principio, pues la marca ha sido especialmente concedida para un titular, el cual puede hacer uso de su derecho extensivamente hacia otras clases y productos en virtud de la notoriedad o renombre de su marca, aún cuando no la tenga registrada en esas otras clases.

En nuestra legislación se contempla que el signo protege el, o los productos para los cuales se ha registrado la marca, no obstante, si un tercero pretende el registro de una marca idéntica o similar se debe considerar si hay semejanza o identidad entre los productos, pues por el principio de especialidad el titular puede oponerse a esta nueva solicitud de registro o más aún, hacer extensivo su derecho a otros bienes o servicios para los que no ha registrado su marca cuando la identidad o semejanza, aún en una clase diferente causen confusión o asociación con respecto a su marca.

De confrontar los artículos 8 b), y 26 e) de la Ley, versus artículo 12 del Reglamento, se aprecian dos visiones diferentes del principio de especialidad en nuestro derecho positivo, una amplia, la de la Ley, y una restringida, la del Reglamento, lo que ha constituido el foco de conflicto en la aplicación práctica de estas normas ${ }^{188}$.

187 Sobre la postura que asumimos en esta confrontación, Vid Infra IV.3.

188 "Artículo 36. A pedido de cualquier persona interesada y previa audiencia del titular del registro de una marca, la autoridad judicial competente, cancelará el registro de una marca cuando ella no se hubiera puesto en uso durante los tres años ininterrumpidos precedentes a la fecha en que se inicie la acción de cancelación. El pedido de cancelación no procederá antes de transcurridos tres años contados desde la fecha del registro inicial de la marca en el país.

La cancelación de un registro por falta de uso de la marca también podrá alegarse al contestar una objeción del registro, o en un procedimiento de oposición, cuando la objeción o la oposición se sustentaran en una marca registrada pero no usada conforme a esta ley, La cancelación será resuelta por autoridad judicial competente, a la cual el Registro remitirá los autos para que la acción se radique en sede sumaria.

Cuando el uso de la marca se iniciara después de transcurridos tres años contados desde la fecha de concesión de su registro en el país, tal uso sólo impedirá la cancelación del registro si se hubiese iniciado al menos tres meses antes de la fecha en que se presente el pedido de cancelación.

Cuando la falta de uso sólo afectara a uno o a algunos de los productos o servicios para los cuales estuviese registrada la marca, la cancelación del registro se resolverá reduciendo o limitando la lista de los productos o servicios comprendidos en el registro, eliminando aquellos respecto de los cuales la marca no se ha usado." El artículo citado fue reformado por la Ley 580, la cual ha sido previamente citada. 


\section{Revista de ODerecho}

Es oportuno resaltar el aspecto contemplado en la Ley de Marcas vigente en Nicaragua; que si bien por el principio de especialidad en sentido amplio, un titular puede oponerse o impedir el registro de una marca idéntica o similar en el supuesto que cause un riesgo de confusión o de asociación; por el requisito del uso, reclamado en la acción de cancelación por falta de uso de una marca se puede cancelar judicialmente el registro de la marca, así como su protección para algunos de los productos para los cuales no se usa, artículo 36, Ley 380, ${ }^{189}$ si bien los artículos estudiados respecto al principio de especialidad, protegen al titular de la marca, el citado artículo 36 está redactado en función de proteger al tercero que ve coartado arbitrariamente su derecho; en este sentido, este requisito de uso, es una garantía tanto para el comercio como para potenciales comerciantes que aspiran irrumpir en el mercado, consideramos que en este sentido, la misma ley ofrece al tercero interesado en el registro de una marca similar o igual, en el supuesto que no cause riesgo de confusión o asociación, una contra garantía.

Queremos resaltar que la protección al titular no es absoluta, ni puede éste hacer prevalecer arbitrariamente su derecho sobre la marca registrada, sino que hay condiciones que debe cumplir con el fin de evitar excesos por parte del titular; entorpeciendo el tráfico comercial al tener marcas de reservas (para usarlas en un futuro si fuera necesario), o marcas de protección (no las usa son marcas en clases similares que le permite oponerse ante un posible registro de una marca similar o igual); por ejemplo, El Cacique en clase 30 para arroz y 31 para semillas no comprendidas en la clase 30.

\section{El riesgo de confusión y asociación}

Siendo el fin del Derecho de Marcas y del objeto de las marcas el individualizar productos y fijarlos en la mente del consumidor, así como un coadyuvante del principio de especialidad, el riesgo de confusión se convierte en aspecto esencial al momento de otorgar o denegar marcas que se contraponen. La figura de la confusión surge íntimamente vinculada al Derecho de Competencia desleal en Europa y a través de jurisprudencia se han ido sentando las pautas al momento de evaluar y juzgar las marcas y si se produce este riesgo.

En nuestra legislación los primeros visos aparecen en el Convenio Centroamericano para la Protección de la Propiedad Industrial, artículo

189 Citado por el Dr. Guy Bendaña Guerrero, en su obra Curso de Derecho Industrial. 
10, literal f), ${ }^{190}$ "No podrán usarse ni registrarse como marcas ni como elementos de las mismas" (...) "Los distintivos que por su semejanza gráfica, fonética o ideológica puedan inducir a error u originar confusión con otras marcas o con nombres comerciales, expresiones o señales de propaganda ya registrados o en trámites de registro, si se pretende emplearlos para distinguir productos, mercancías o servicios comprendidos en la misma Clase". Como puede apreciarse es abordado de manera basta y con un enfoque material, el riesgo de confusión, pues lo alude relacionándolo con las marcas; no en la relación marca-sujeto destino del bien identificado por la marca.

La nueva Ley de Marcas, Ley 380 y su Reglamento, continúa expresando el mismo enunciado, sin embargo agrega un nuevo elemento; entrelaza el principio de especialidad con el sujeto al que va dirigida su protección al establecer los artículos 8 de la Ley y 12 del Reglamento, que la protección que la Ley brinda al titular de la marca con miras a proteger al destinatario de los bienes que se pretenden distinguir a fin de que claramente pueda diferenciar la procedencia del producto o servicio sin ser llamado a confusión o asociación.

Consideramos que el riesgo de confusión tal como es contenido en el Derecho de Marcas español que es producto y recoge los lineamientos de la Primera Directiva 89/104/CEE cuyo propósito es armonizar la legislación comunitaria en materia de marcas, debe ser considerada con respecto al signo distintivo, al producto o servicio y a la clase en la que están contenidos.

Aborda nuestra Ley de Marcas el riesgo de confusión y asociación como figuras independientes; pudiéndose incurrir en una o la otra; por el contrario la Primera Directiva 89/104/CEE y la Ley de Marcas Españolas al respecto dicen: "Que, por ser idénticos o semejantes a una marca anterior y por ser idénticos o similares los productos o servicios que designan, exista un riesgo de confusión en el público; el riesgo de confusión incluye el riesgo de asociación con la marca anterior”.

El riesgo de asociación se inserta en las nuevas legislaciones específicamente en la europea a través de la Primera Directiva 89/104

190 El 30 de noviembre de 1994, los Ministros de Centroamérica excepto el de Honduras firmaron en San Salvador, El Salvador, el Protocolo de Modificación al Convenio Centroamericano para la Protección de la Propiedad Industrial. 
CEE y en Nicaragua en el Protocolo de Modificación al Convenio Centroamericano ${ }^{191}$ el cual sirvió de base para la elaboración de la Ley 380, Ley de Marcas de Nicaragua; decía el Protocolo en su artículo 9. Marcas inadmisibles por derechos de terceros:

a) "No podrá ser registrado como marca un signo cuando ello afectara algún derecho de tercero, entre otros en los siguientes casos: (...)

b) Si el uso del signo fuera susceptible de causar confusión por ser idéntico o similar a una marca registrada o en trámite de registro por un tercero desde una fecha anterior y que distinguiera los mismos productos o servicios o productos o servicios diferentes pero susceptibles de ser asociados con los que la marca anterior distingue;

c) Si el uso del signo fuera susceptible de causar confusión por ser idéntico o similar a una marca usada por un tercero que tiene mejor derecho a obtener su registro y que se usara para los mismos productos o servicios o productos o servicios diferentes pero susceptibles de ser asociados con los que la marca en uso distingue." La citada norma sugiere que la confusión es producto del uso de un signo, registrado o no, idéntico o similar a la marca registrada para distinguir los mismos productos o servicios (identidad o semejanza de signos e identidad de productos) y la asociación es fruto del uso de un signo, registrado o no, idéntico o similar a la marca registrada para distinguir productos o servicios diferentes.

Con lo expresado en el Protocolo de Modificación al Convenio Centroamericano, confusión y asociación son dos situaciones independientes que se pueden producir, una no conlleva a la otra; sin embargo reiteramos nuestras consideraciones: La una (asociación) es el origen que desencadena la confusión; así al tratar de definir la dimensión conceptual de las marcas gráficas Fernandez-Novoa dice que "la marca puramente gráfica es aquella que se limita a suscitar en la mente de los consumidores tan solo la imagen del correspondiente signo que se utiliza como marca. Al contemplar este tipo de marca, el consumidor no asocia la misma con ningún ser u objeto concreto o abstracto. Antes al contrario, el consumidor asocia tal marca simplemente con una imagen o figura que se caracteriza por un conjunto de líneas o, en su caso, por un conjunto de líneas y colores." Esto está referido a la consecuencia de lo que provoca un signo gráfico en la mente del consumidor, sin embargo,

191 FERNANDEZ-NOVOA, Carlos, Tratado sobre Derecho de Marcas, Madrid, Marcial Pons, 2004, pág. 370. 


\section{Revisla de Derecho}

de aquí se desprende que primero ocurre la actividad de asociación para luego producir un efecto; trasladándolo al riesgo de asociación/ confusión consideramos que ambos riesgos son independientes y por tanto, se puede caer en uno u otro; y en los casos en que se produzca asociación, esta conlleva a la confusión, aunque esta última también pueda suscitarse independientemente que exista asociación; la confusión es instantánea, la confusión es un riesgo inminente frente a dos marcas que presentan similitudes visuales, ortográficas y fonéticas.

Como quedó dicho ut supra, el concepto de riesgo de asociación irrumpe en el Derecho de Marca europeo a través de la Directiva 89/104 CEE y ha creado disímiles interpretaciones y tesis. En la Propuesta de la Directiva se consideró el presupuesto: "riesgo serio de confusión en la mente del público", quedando finalmente en la Directiva "riesgo de confusión que comprenda el riesgo de asociación con la marca anterior".

Con el propósito de interpretar el espíritu de nuestro legislador nos adentraremos a revisar lo que los tratadistas europeos han recabado sobre la aparición e inclusión del riesgo de asociación en el Derecho Comunitario de marcas. El artículo 13(A)1 de la Ley Uniforme de Marcas del Benelux "no mencionaba el riesgo de confusión: aludía únicamente a la semejanza de la marca con el signo y la identidad o similitud de los productos o servicios" ${ }^{192}$. Es en la interpretación de este artículo que no tocaba siquiera el riesgo de confusión, que la jurisprudencia del Tribunal del Benelux deja sentada y formula la siguiente doctrina:

"Existe semejanza entre una marca y un signo cuando a la vista de las circunstancias del caso, singularmente de la fuerza distintiva de la marca, la marca y el signo, considerados en símismos y en sus relaciones recíprocas, presentan en el plano auditivo, visual o conceptual una semejanza de tal naturaleza (semejanza de signos) que es apta para evocar una asociación entre el signo y la marca".

¿Podemos inferir entonces que nuestra Ley considera como válida la jurisprudencia del Benelux y acoge como aspectos diferentes confusión y asociación; conjugando la jurisprudencia del Benelux en cuanto al riesgo de asociación y la legislación marcaria comunitaria en cuanto al riesgo de confusión, tal como era planteada en las propuestas previas a la elaboración de la Primera Directiva?.

192 FERNANDEZ-NOVOA, Carlos, Tratado sobre Derecho de Marcas, Madrid, Marcial Pons, 2004, pág. 376. 


\section{Revista de ODerecho}

Consideramos que efectivamente, nuestros legisladores quisieron regular como aspectos diferentes asociación y confusión, sin que uno conlleve al otro; más bien se presentan como aspectos independientes que ocurren uno sin la presencia del otro; concluimos entonces que siguió las propuestas previas a la elaboración de la Primera Directiva, la cual en un afán de conciliar dos posiciones que se suscitaron entre los diferentes países, acogió los dos riesgos; sin embargo, el de confusión comprende el de asociación, en confrontación a lo sostenido por los holandeses; dicha redacción ha motivado diferentes interpretaciones. Actualmente se sigue en la doctrina y jurisprudencia Europea, independientemente de lo dicho por la jurisprudencia del Benelux, dos tesis:

1. Tesis sobre un concepto amplio del riesgo de asociación. Concebido por la doctrina holandesa, que propugna que el riesgo de asociación es más amplio que el de confusión, según esta concepción cabe el supuesto que el público considere que entre el titular de la marca y quien la usa exista algún vínculo o relación contractual tal como licencias de uso, franquicia, entre otros. El consumidor o usuario diferencia entre los bienes y su origen, sin embargo "establece conexiones o asociaciones basadas en el hecho de que la percepción del signo desata el recuerdo de la marca." "193

2. Tesis que entronca el riesgo de asociación con el riesgo de confusión. Esta segunda tesis es defendida por la doctrina y jurisprudencia alemana, esta corriente propugna la confusión mediata o indirecta, la cual es el equivalente a la asociación, en este supuesto el consumidor diferencia las marcas, no obstante puede incurrir en error al creer que las marcas confrontadas pertenecen a un mismo empresario. La misma doctrina alemana dentro del riesgo de asociación contempla la confusión lato sensu, según la cual el consumidor diferencia las marcas confrontadas y los titulares, sin embargo cree que entre las empresas existen vínculos.

3. La doctrina sentada en el caso "Sabel BV contra Puma AG. Si bien el Tribunal rechaza la tesis del Benelux acoge implícitamente o sienta la pauta para adherirse en el futuro a la tesis de que el riesgo de asociación comprende el riesgo de confusión indirecta y el de confusión lato sensu. El Tribunal descarta la tesis de que el riesgo de asociación constituye una figura distinta al riesgo de confusión.

193 FERNANDEZ-NOVOA, Carlos, Tratado sobre Derecho de Marcas, Madrid, Marcial Pons, 2004, pág. 372. 


\section{Revista de Derecho}

Coincidimos con lo expresado por la doctrina holandesa referente a la redacción del artículo 4.1.b dela Directiva, "elminus (riesgo de confusión) propugnado por muchas delegaciones incluye dentro de sí el plus (riesgo de asociación) propugnado por la delegación del Benelux". ${ }^{194}$ La Primera Directiva para el acercamiento de las legislaciones comunitarias en un afán de integrar las dos posiciones, la del Benelux y la de la Comisión de las Comunidades Europeas insertan como una categoría del riesgo de confusión, la asociación, tal como si esta fuera una de las tantas maneras que conllevan a la confusión.

Por el contrario consideramos que en virtud de la asociación de los signos que se produce en la mente del consumidor, ésta induce o lleva a la confusión; así lo considera también una parte de la doctrina al expresar "De acuerdo con la jurisprudencia comunitaria el riesgo de asociación que produce la nulidad relativa de la marca no es la mera conexión mental que el consumidor puede efectuar entre dos marcas; es necesario, además, que el consumidor pueda caer en confusión acerca de la procedencia empresarial de los productos o servicios”. ${ }^{195}$

En concreto, consideramos que nuestra ley, en beneficio de derechos anteriores concedidos, no admite marcas que provoquen un riesgo de confusión o asociación, que pongan en riesgo la especialidad de la marca registrada. Consideramos que se debe extender o ir un poco más allá en el criterio evaluador, no quedarnos únicamente en la letra de la ley, más específicamente a lo propugnado por el artículo 12 del Reglamento; circunscritos en que la especialidad es para el producto al que ha sido destinado solamente y por tanto la confusión o asociación solo se puede producir en este contexto; y fuera de ello no cabe o no es posible caer en estos supuestos. Por el principio de especialidad la protección a derechos anteriores sobre un signo, trasciende los límites de una clase o productos o servicios.

\section{1.¿Confusióny asociacióningredientes deuntodoopartes segmentadas?}

Es un punto central y el que más subjetividad y dificultad plantea en la práctica; los medios, aspectos, normas y criterios para determinar el

194 URÍA, Rodrigo/MENÉNDEZ, Aurelio, Curso de Derecho Mercantil, Madrid, Civitas, 2001, pág. 371 y 372.

195 Sentencia del Tribunal de Justicia de las Comunidades Europeas que falló el caso "Sabel BV contra Puma AG Rudolff Dassler Sport” asunto C251/1995. apartado 6, párrafo tercero; proporcionada en Maestría de Derecho de Empresas, Módulo de Derecho de Marcas impartido por el Prof. Fernando Carbajo Gascón, año 2008. 
riesgo de Confusión. ¿Qué es lo que en sí puede llevar a confusión, la semejanza de los signos, la semejanza de los productos? Sí, pero ¿Cómo "medir" la semejanza? Pasamos directamente al riesgo de confusión entre signos semejantes puesto que entre signos idénticos es más que obvio este riesgo.

En cuanto a los signos similares, no hay un código que establezca de manera taxativa los criterios a evaluar, sino que sigue algunas líneas que poco a poco se han trazado y finalmente queda a la apreciación de la autoridad que le toca fallar el caso; sin embargo, "debiéndose respetar las pautas que dicta la lógica o la experiencia"196. Así una de estas líneas es "la impresión global producida por uno y otro signo"197. A este respecto consideramos que no es tan precisa esta pauta ya que en un signo, sobre todo si es figurativo o mixto, hay aspectos del signo que sobresalen y se deben tener como los rasgos o aspectos relevantes o principales de la marca, sin embargo, hay reglas que nos permiten orientarnos a tal efecto.

Debemos además considerar que nuestra Ley de Marcas estatuye como una razón para denegar el registro de una marca por considerarla inadmisible cuando ponga en riesgo el derecho de un tercero por razones de provocar riesgo de confusión o asociación; nuestra ley al utilizar una expresión disyuntiva nos lleva a creer que el legislador nicaragüense percibe como figuras independientes y diferentes dichos riesgos; confusión, asociación y no que una subsuma a la otra.

Ante la posibilidad de confusión o asociación de los signos debe haber un doble contraste; se debe analizar si los signos son similares o idénticos y además si los productos o servicios que pretende distinguir tienen a su vez similitud o identidad. La prohibición al registro de la marca será absoluta, cuando haya una doble identidad: identidad del signo e identidad de los productos o servicios amparados por la marca ${ }^{198}$.

196 Sentencia del Tribunal de Justicia de las Comunidades Europeas que falló el caso "SabelBV contra Puma AG Rudolff Dassler Sport" asunto C251/1995. apartado 6, párrafo primero; proporcionada en Maestría de Derecho de Empresas, Módulo de Derecho de Marcas impartido por el Prof. Fernando Carbajo Gascón, año 2008.

197 Al respecto Fernández-Novoa, Carlos. Tratado sobre Derecho de Marcas, pág. 242, siguiendo al actual Derecho europeo de Marcas, cataloga este aspecto otorgándole el rango de prohibición autónoma y lo recoge la actual Ley de Marcas española.

198 Marcas anteriores.- 1. No podrán registrarse como marcas los signos: a) Que sean idénticos a una marca anterior que designe productos o servicios idénticos". 
A nuestro pesar la prohibición absoluta (entendida ésta como ex oficio) a la que alude la Ley de Marcas española en su artículo 6 apartado 1, literal a; no se encuentra en nuestra Ley; ${ }^{199}$ en la Ley de Marcas de Nicaragua, artículo 8, inc. b queda abierta la posibilidad de registro para la marca posterior si ella "no causara riesgo de confusión o de asociación"; estando por demostrarse el perjuicio que pudiera causar el registro de la marca posterior; en nuestra ley no opera la doble identidad: identidad de los signos y de los productos o servicios, tanto en las prohibiciones como el derecho que confiere el registro de la marca, artículo 26, Ley de Marca y otros Signos Distintivos; queda al titular de la marca demostrar o exponer las razones por las cuales no se debe permitir el registro basado en el riesgo de confusión o asociación que pudiera propiciar; no opera de mero derecho en nuestra ley.

En virtud de lo antes expuesto, un tercero puede intentar el registro de una marca idéntica para productos idénticos o semejantes y conllevar esta situación, al procedimiento administrativo en todas sus fases hasta llegar al máximo tribunal de justicia con el Recurso de Amparo ante la Corte Suprema de Justicia provocando así un largo proceso que representa la manera más clara, abierta e inescrupulosa de pretender obtener un registro de una marca igual a otra previamente registrada; decimos inescrupulosa pues consideramos que no se puede llamar de otra manera a la intención de registro de una marca idéntica para productos idénticos, pues con una sencilla operación de búsqueda telemática en las propias oficinas de la institución se puede constatar la disponibilidad de un signo; y si es un abogado diligente o un empresario que persigue las buenas prácticas comerciales solicitará el aviso de novedad o mejor conocido como búsqueda de antecedentes registrales, que si bien no es un certificado que pueda ser esgrimido como prueba, si deja constancia de la buena fe del pretensor del registro.

El riesgo de confusión y asociación se presenta en nuestra ley como figuras independientes o bien el de asociación que conlleva o produce la Confusión, la línea seguida por la doctrina alemana. En este sentido es posible que el legislador haya intentado establecer el riesgo de confusión inmediata o directa, según la cual el público consumidor tiene un

199 MARTÍNEZ MEDRANO, Gabriel/SOUCASSE, Gabriela, Derecho de Marcas, Ediciones La Roca, Buenos Aires, 2000, Pág. 85 


\section{Revista de ODerecho}

conocimiento errado de la realidad que se presenta ante sus sentidos y por descuido toma el bien equivocado convencido que está obteniendo otro del cual ya tiene referencias, confunde las marcas; o bien, incurre en asociación cuya expresión puede ser confusión indirecta o confusión lato sensu.

2. La identidad o semejanzas de los signos confrontados como supuesto de confusión o asociación

Con el propósito de poder establecer el riesgo de confusión-asociación que se puede suscitar entre dos signos que presenten "rasgos" coincidentes, la doctrina ha elaborado parámetros para facilitar dicha tarea; recalcando inicialmente que se deben tener en cuenta las semejanzas que presentan las marcas confrontadas y no las diferencias, pues lo que se pretende establecer son las semejanzas que llevan al consumidor a la confusión y a obtener productos y servicios equivocados; al respecto dicen Martínez Medrano-Soucasse: "Existen reglas para orientar al analista en el cotejo, con una elaboración basada en la jurisprudencia. En tal sentido se ha resulto que las marcas similares, cuya coexistencia está vedada por la ley son las que producen un riesgo o posibilidad de confusión en el mercado, la confusión se produce cuando cotejando una marca después de la otra dejan el mismo recuerdo, la misma impresión, aún cuando en los detalles existan diferencias..." ${ }^{200}$.

Inicialmente los tipos de semejanzas eran enunciados en la Ley; así, el apartado primero del artículo 12 de la Ley española de Marcas de 1988 se refería expresamente al dato de la identidad o semejanza, fonética, gráfica o conceptual ${ }^{201}$.

En nuestra legislación marcaria no se aprecia esta clara alusión a los tipos de semejanzas en las marcas, pero sí ha sido recogida por la jurisprudencia; así lo vemos en la sentencia número 34 de las 12:30 p.m. del 5 de junio de 1997, la cual dice: "Recuerda esta Sala la Sentencia

200 FERNÁNDEZ-NOVOA, Carlos, Tratado sobre Derecho de Marcas, ed. Marcial Pons, 2da. Ed. Madrid, 2004, pág. 291. "no podrán registrarse como marcas los signos o medios: a) Que por su identidad o semejanza fonética, gráfica o conceptual con una marca anteriormente solicitada o registrada para designar productos o servicios idénticos o similares puedan inducir a confusión en el mercado o generar un riesgo de asociación con la marca anterior."

201 MARTINEZ-MEDRANO,Gabriel/SOUCASSE, Gabriela, Derecho de Marcas, Ediciones La Roca, Buenos Aires, Argentina, 2000, pág. 88 y ss. 
No. 85, de las diez y cuarenta y cinco minutos de la mañana del día veinticuatro de Octubre de mil novecientos noventa y cuatro, que al referirse a los Convenios Centroamericanos para la Protección de la Propiedad Industrial y la Convención Interamericana de Protección Marcaria y Comercial señaló que habiendo sido suscrito, el primero de dichos Convenios, por los Gobiernos de Guatemala, El Salvador, Honduras, Nicaragua y Costa Rica, éste tiene como uno de sus objetivos la protección y garantía de las personas naturales o jurídicas, que han dado cumplimiento a la obligación legal de registrar una marca de fábrica, en el respectivo Registro de la Propiedad Industrial, invocando tanto el dominio sobre la marca, como para promover oposición al registro de otra marca, solicitado por un tercero, cuyos distintivos, semejanza fonética o ideológica, puedan ocasionar confusión, con otras marcas o nombres comerciales."

Así llegamos a lo expresado por la sentencia número 85 de las 10:45 a.m. del 24 de octubre de 1994, la cual en el cuarto considerando expresa: "Por tales motivos este Supremo Tribunal en sentencia dictada a las once de la mañana del diecinueve de enero de mil novecientos cuarenta y ocho, en el considerando tercero manifestó lo siguiente: "Y aún más, se llegó a la misma Convención hasta prohibir y considerar como causal de negativa, el uso de palabras que formaban el todo o parte del nombre comercial de la persona natural o jurídica que se dedicara a la fabricación o comercio del mismo producto; se ve pues, que lo que se ha querido evitar es toda semejanza entre la marca que se pretende registrar y la ya registrada, sea esta semejanza gráfica, fonética o de identidad parcial o total de las palabras componentes."

Cabe observar que ambas sentencias abordan las semejanzas gráficas y fonéticas, no así las conceptuales y es así también contemplado en la jurisprudencia extranjera, al respecto dice Fernández-Novoa: " $L a$ necesidad de atender a la semejanza conceptual entre las marcas enfrentadas debe ser especialmente destacada, porque un sector predominante de la jurisprudencia contencioso-administrativa del Tribunal Supremo español relega a un plano secundario el dato de la identidad o semejanza conceptual de las marcas comparadas."

Se ha planteado que la identidad o semejanzas de los signos puede traer aparejado un riesgo de confusión o asociación y ese es el espíritu del art. 8 inciso b y los artículos 26 de la Ley 380, todos de la Ley de Marcas. 


\section{Revista de ODerecho}

Cuando una semejanza anuncia confusión dependerá del tipo de semejanza de que se trate y en este sentido la doctrina ha establecido distintos criterios de semejanzas que a continuación serán expuestos.

2.1. Tipos de semejanzas

\subsubsection{Semejanzas entre signos}

- Semejanzas gráficas: También abordadas como semejanzas visuales; debemos dejar claro que dentro de las semejanzas gráficas debemos considerar las marcas puramente gráficas y las marcas figurativas; la diferencia entre una y otra es que las puramente gráficas están constituidas por trazos, líneas y colores provocando en la mente del consumidor tan solo la imagen que constituye la marca; la marca figurativa es la constituida por una imagen que representa un ente propio del entorno humano, el cual forma parte de sus experiencias sensoriales suscitando en los consumidores además de la imagen visual, un concepto una idea.

Las semejanzas gráficas se producen en virtud de similitudes al sentido de la vista que presentan las marcas y que son producto de la intención del solicitante pretensor o bien producto de un descuido o negligencia de aquel al no realizar una búsqueda de antecedentes registrales, cuyo objeto es el principio de novedad, estas similitudes que conllevan a la confusión son:

i. Similitud ortográfica: relativo a las sílabas o palabras que componen la marca; en este punto se deben considerar la raíz y la desinencia de la palabra que conforman la marca; es aceptado en la doctrina argentina que la raíz es la parte del signo que el consumidor retiene en su mayoría en la mente; por lo tanto "Si existe identidad de raíz existe posibilidad de que haya confusión" ${ }^{202}$. Al respecto consideramos que no aclara, pero sí aporta más elementos o razones esta valoración hecha por los autores, siguiendo la línea jurisprudencial, ya que igual se mantiene la ambigüedad y la posibilidad para ambas partes de poder argumentar su posición y al final quedar a la consideración del juzgador si en efecto se produce la similitud o no; al respecto dicen los autores argentinos: "Los tribunales han observado con disfavor la similitud silábica entre las marcas, especialmente cuando las semejanzas en cuanto al orden, grafía y fonética, estaban radicadas en las primeras sílabas o en las primeras letras, dando lugar a la

202 Citando el caso CNFed. Civ. Y Com., 29/7/60, "Standard Electric Argentina c/Esso" 


\section{Revista de Derecho}

existencia de prefijos comunes cuya coexistencia está condicionada a la de desinencias suficientemente distintivas que superen la igualdad de los radicales" ${ }^{203}$.

Se perfila este tipo de semejanza un poco más cuando se atienden dos razones: la importancia de la raíz considerada como el aspecto de mayor relevancia frente a si ésta es de uso común en la clase, bien por ser descriptiva para esos bienes o servicios o ya por que resulta descriptiva o bien porque la raíz ha sido solicitada y otorgada para un cierto número de marcas propiedad de diferentes titulares, al efecto la doctrina argentina establece un número: diez marcas registradas convirtiéndola de uso común en la clase.

Consideramos en este punto que si se produce una similitud gráfica en la subcategoría ortográfica conlleva similitud fonética, al efecto existen similitudes fonéticas aunque no ortográficas al utilizar símbolos o caracteres que pronunciados en otro idioma producen similitud fonética es conocido el caso en la jurisprudencia nicaragüense VAPO RUB v. VAPO II ${ }^{204}$, en ambos signos la raíz es igual, sin embargo las desinencias gráficamente difieren; no obstante, al pronunciarlas se escucha VAPO RUB - VAPO TWO y aún más las desinencias son de la lengua inglesa que en nuestro país se escuchan: ru, tu; así tenemos el fonema vaporú contra vapotú; existe similitud fonética, aunque en un primer momento se puede presumir que no hay similitud gráfica ya que las desinencias son visualmente diferentes.

ii. Similitud gráfica: relativo a los dibujos o trazos, grafía especial; no debe confundirse esta categoría de similitud con la ortográfica, pues no es la disposición de letras o sílabas en donde se presenta la similitud, sino en el tipo de letra. Es de destacar que esta situación no es muy frecuente; al respecto no hay muchos casos en la

203 Sentencia 120 de las 10:00 a.m. del 17 de diciembre de 1990; consultado en formato digital elaborado por la Corte Suprema de Justicia.

204 Artículo 9, numeral 2 de la Ley 380, Ley de Marcas y Otros Signos Distintivos. Solicitud de Registro. La solicitud de registro de una marca se presentará ante el Registro y comprenderá lo siguiente: (...) 2. Una reproducción de la marca en cuatro ejemplares cuando ella tuviera una grafía, forma o color especiales, o fuese una marca figurativa, mixta o tridimensional con o sin color.

Artículos 7 del Decreto número 83-2001 Reglamento de la Ley de Marcas y Otros Signos Distintivos. Marca Tridimensional. Cuando la marca fuese tridimensional, la reproducción de la marca consistirá en una reproducción grafica o fotográfica bidimensional. La reproducción podrá consistir en una vista única o en varias vistas diferentes.

Artículo 14 Decreto número 83-2001 Reglamento de la Ley de Marcas y Otros Signos Distintivos. Marca Figurativa, mixta o tridimensional. Cuando la marca fuera figurativa, mixta o tridimensional, la solicitud de registro podrá indicar las categorías y divisiones pertinentes de la clasificación internacional referida en el articulo 94 de la Ley. 
jurisprudencia europea ya que en la práctica la solicitud de marcas puramente gráficas no es muy frecuente; consideramos que la razón se debe a que no evoca un concepto o idea en el consumidor; es más difícil fijarla en su mente, lo que provoca una mayor inversión en publicidad por una extensión de tiempo mayor.

iii. Similitud de forma: relativa a los envases, en la misma sentencia a la que se ha hecho alusión en el apartado anterior, se menciona la imitación que la marca VAPO II hace del envase: "Que la titular del registro de la marca VAPO II, no solamente imitó la marca en sí, sino que también el envase y el cartón registrados a favor de su mandante con el No. 23539, dándole la misma forma, poniéndole los mismos colores y leyendas casi iguales, como lo demostraría en su oportunidad". Este tipo de similitud cabe dentro de la similitud visual y al mismo tiempo conceptual, pues ella comprende la forma de los envases, los colores utilizados y las leyendas empleadas en las etiquetas adheridas a dichos envases o impresas en los envoltorios o cajas que contienen los envases con el producto; nos hemos enfocados en productos puesto que se requiere de materialidad para poder percibir los elementos planteados, los que no concurren en las marcas que amparan servicios. Al hablar de los envases que contienen los productos pasamos a una nueva categoría de signos distintivos, las marcas tridimensionales para efectos de una mejor comprensión del término buscaremos una definición de marcas tridimensionales, ya que nuestra legislación solamente regula lo concerniente a la marca tridimensional en lo que respecta a la solicitud de ella y su reproducción. ${ }^{205}$

"¿Qué se entiende por marca tridimensional? la respuesta sería la siguiente: "Puede constituirse en una marca tridimensional, la forma de un producto, sus envases o envolturas siempre y cuando distinga el producto y no corresponda a una forma usual en el mercado. El signo debe gozar de distintividad frente al producto. El derecho conferido es virtualmente perpetuo, en tanto se renueve de conformidad con las disposiciones legales."

Otra definición mas escueta de marcas tridimensionales sería: "las marcas tridimensionales se corresponden con cuerpos representados

$205 \mathrm{La}$ frontera entre marcas tridimensionales y diseños industriales. Monografías.com [Consultado en línea] 10 de noviembre 2008. http://www.monografias.com/trabajos45/marcas-tridimensionales/ marcas-tridimensionales.shtml 
en 3 dimensiones, como envases, envoltorios, botellas, cajas, la forma de un producto, siempre y cuando distinga el producto y no corresponda a una forma usual en el mercado.

Una tercera definición de Marca tridimensional, y que se hace referencia a las dimensiones o medidas que ocupa la marca, en el espacio es: "aquel signo que posee volumen (alto, ancho y profundidad), o sea, que ocupa per se un espacio determinado".

Como se puede apreciar en casi todas las definiciones hay elementos que se repiten como son: la forma del producto, envases o envoltorios, que de distintividad al producto y que no corresponda con una forma usual en el mercado"2o6.

- Fonéticas: Según el plano de semejanza fonética, también conocido como semejanza auditiva se debe considerar la pronunciación común del consumidor local; referido al idioma del país en el cual se solicita la marca.

La jurisprudencia argentina considera que es suficiente que haya riesgo de confusión fonética para denegar el registro de una marca posterior similar fonéticamente a otra previamente registrada, aunque no concurran otros tipos de semejanzas; "es suficiente la responsabilidad razonable de confusiones en cualquiera de las esferas del cotejo para que se justifique cohibir la concurrencia marcaria.” ${ }^{207}$

Expresa la doctrina argentina que se considera relevante la similitud fonética, en los puestos de ventas de productos al por menor, en comercios pequeños; "ventas" o pulperías en nuestro caso particular; a donde acude el consumidor y solicita los productos por su nombre común y lo detalla o especifica la calidad que requiere por la marca: por ejemplo solicita arroz; sin embargo, para el arroz hay diferentes calidades 96/4, $80 / 20,70 / 30,60 / 40$ (porcentaje de grano entero y grano quebrado) y cada una de ellas se diferencian por marcas; así tenemos, Faisán, Doña María, Güegüense y Delfín.

206 MARTÍNEZ-MEDRANO, Gabriel/SOUCASSE/Gabriela, Derecho de Marcas, 2da ed., Ediciones La Roca, Buenos Aires, Argentina, 2000, pág. 91.

207 Sentencia 120 de las 10:00 a.m. del día 17 de diciembre de 1990. Consultado en formato digital elaborado por la Corte Suprema de Justicia. 


\section{Revista de Derecho}

- Conceptuales o ideológicas: Este plano de confusión es el más atendido y en el que la jurisprudencia extranjera ha puesto más atención y énfasis.

Consideramos que este plano es el más elaborado, en el sentido que provoca una serie de procesos en las personas a quienes va dirigida la marca, es de aquí donde se produce la asociación que puede venir de una imagen, un sonido, un olor; por tanto la confusión ideológica se puede desencadenar a través de los sentidos por los que percibimos las marcas.

Así en la jurisprudencia nacional ya hay opiniones en este sentido: "Que las marcas de su mandante (VAPO RUB) y la marca VAPO II, amparan productos de naturaleza similar y son sustancialmente parecidas, puesto que para formar ésta se tomó la parte esencial, VAPO, de las marcas de su representada, produciéndose una confusión visual, fonética e ideológica. Por otra parte, los productos que distinguen las marcas referidas se expenden en el mismo tipo de establecimientos, produciéndose así mayor número de probabilidades de confusión en el público" ${ }^{208}$. Como podemos apreciar en esta sentencia de la Corte Suprema de Justicia de Nicaragua, se contempla el riesgo de confusión ideológica que provoca el uso de la palabra VAPO en las marcas confrontadas y puesto que son utilizadas para proteger en ambos casos productos medicinales, propios de la clase 5, "especialmente un ungüento medicinal para catarros, resfríos, picaduras de insectos, etc." Trayendo así a la mente del consumidor la idea o concepto de VAPO y su efecto calmante ante situaciones de constipación nasal o escozor por las picaduras de insectos.

Cabe hacer en este momento una segmentación o separación del aspecto conceptual de las marcas partiendo de si estas son denominativas o gráficas.

i) Dimensión conceptual, marcas denominativas: Partimos desde la perspectiva semántica de las palabras que conforman las marcas denominativas, según éstas pueden tener un significado o carecer de él.

La jurisprudencia española se ha dividido en cuanto a la preponderancia de las semejanza conceptual o ideológica; por una parte, el sector

208 Sentencia de la Sala Primera del Tribunal Supremo de 30 de noviembre de 1990, citada por FernandezNovoa en su obra Tratado sobre Derecho de Marcas, pág. 295. 
mayoritario sostiene que al atender a la semejanza conceptual debe ser como un criterio complementario; sin embargo, consideramos que debe tenerse en cuenta que es así cuando se hace uso de palabras que carecen de un significado y son una mezcla de letras o sílabas caprichosas; en tal caso si debe complementar o se debe prescindir del aspecto conceptual o ideológico de la denominación; sin embargo cuando ambas denominaciones poseen un significado en nuestro idioma, sí juega un papel fundamental la semejanza conceptual.

Por otra parte la línea jurisprudencial minoritaria, según la cual otorga un importante relieve al aspecto conceptual o ideológico de las marcas sostiene que: "la confrontación de marcas ha de ser global y no fragmentaria, de suerte que la literalidad de las denominaciones y los gráficos o diseños no pueden ser cotejados por separado y el enfrentamiento ha de ser en su triple vertiente; visual, auditiva o fonética y literaria" ${ }^{209}$; entendida esta última, como el medio a través del cual nos expresamos, el lenguaje o el idioma que está formado por conceptos expresados en palabras. Compartimos esta aseveración con la salvedad que ésta es válida para los signos denominativos que forman parte de nuestro idioma o en un idioma extranjero que ya ha sido incorporado en el uso cotidiano y que la generalidad de la población a la que va dirigido el producto conoce y comprende, tal es el caso de baby, mouse; por citar algunas; y por lo tanto sí tienen un significado, una connotación conceptual; también cabe en el caso de marcas compuestas de dos palabras, ejemplo: dulcipan.

Pese a ser la corriente minoritaria, nos adherimos a ella pues se debe partir del análisis completo e integral, desde todos los ámbitos posibles de semejanza; además consideramos que las ideas y conceptos son uno de los aspectos más importantes en el aprendizaje de la persona, a través de ellos se fijan preferencias, gustos y comportamientos frente a una situación en este caso frente a un producto o servicio.

ii) Dimensión conceptual, marcas gráficas: para proceder a analizar esta dimensión haremos referencia al apartado del presente trabajo, Tipos de semejanzas, a) Semejanzas gráficas en el que se diferencia entre marcas puramente gráficas y marcas figurativas. La doctrina española parte de que la dimensión conceptual del signo es inaplicable

209 Sentencia 120, de las 10:00 a.m. del 17 de diciembre de 1990; consultada en formato digital elaborado por la Corte Suprema de Justicia. 
a las marcas puramente gráficas ya que están desprovistas de una imagen o una idea; por lo que pasamos a las marcas figurativas. Éstas por el contrario si provocan en la mente del consumidor una imagen visual y un concepto, el cual generalmente es un concepto concreto, el cual se puede convertir en un concepto abstracto y pasar así de lo específico a lo general produciéndose en este momento el riesgo de confusión; se observa esta apreciación que es propia de la doctrina alemana en la sentencia Sabel BV contra Puma AG, Rudolph Dassler Sport; en la cuestión prejudicial que presentó el Tribunal Supremo alemán ante el Tribunal de Justicia de las Comunidades Europeas se preguntaba: "¿Es suficiente para afirmar la existencia de un riesgo de confusión entre, por una parte, un signo compuesto de un vocablo y una imagen $y$, por otra, un signo compuesto solo por una imagen, que ha sido registrado para productos idénticos y similares y no disfrutan de una especial notoriedad en el mercado, el hecho de que existan entre ambas imágenes una concordancia conceptual (en este caso, un felino saltando)?” Según la decisión prejudicial del Tribunal de Justicia, resulta "que el riesgo de confusión es tanto más elevado cuanto mayor resulta ser el carácter distintivo de la marca anterior. Por consiguiente no puede excluirse que la similitud conceptual derivada del hecho de que dos marcas utilicen imágenes que concuerdan en la idea representada pueda crear un riesgo de confusión en caso de que la marca anterior posea un carácter distintivo particular, bien intrínseco, o bien gracias a la notoriedad de que goza entre el público".

Se expresa en esta sentencia que debido a la falta de notoriedad, fuerza distintiva o falta de prestigio entre el público destinatario de la marca Puma (en ese momento que se ventilaba la controversia); no trasciende el plano concreto para situarse en un plano abstracto que permita la confusión entre las marcas, pues en ambas marcas quedaba claro que una es la representación de un puma y la otra de un leopardo; por lo tanto no podía haber confusión.

La asociación que se hace de una marca figurativa con los productos que protege deviene del concepto o idea evocado por la marca en sí o bien por el segmento de productos o servicios al que se ha destinado, el prestigio alcanzado entre ese segmento.

Reiteramos y mantenemos que primero se produce una asociación entre los productos y servicios, entre los signos y posteriormente esta conlleva o no a confusión. 


\section{Reuista de Derecho}

\subsubsection{Semejanza entre productos o servicios}

A diferencia de lo que inicialmente sucedía en la jurisprudencia española, la cual dejaba de lado la semejanza entre los productos y servicios y ponía especial énfasis en la semejanza entre los signos distintivos confrontados, la jurisprudencia nicaragüense si ha considerado en reiteradas sentencias, la semejanza de productos como fuente de confusión:

"Que las marcas de su mandante y la marca VAPO II, amparan productos de naturaleza similar y son sustancialmente parecidas, puesto que para formar ésta se tomó la parte esencial, VAPO, de las marcas de su representada, produciéndose una confusión visual, fonética e ideológica. Por otra parte, los productos que distinguen las marcas referidas se expenden en el mismo tipo de establecimientos, produciéndose así mayor número de probabilidades de confusión en el público" ${ }^{210}$.

“(...) oponiéndose a la marca solicitada por la doctora Miranda de Malespin, argumentando la evidente semejanza de la marca solicitada con la marca "PINO SOL" No. 16803, clase 3" ${ }^{211}$.

"Que el nombre comercial MAS X MENOS Y DISEÑO de su mandante y el de DISTRIBUIDORA MAS POR MENOS No. 20.475 C.C., protegen actividades comerciales de diferentes índole, pues mientras el primero protege sus productos, continentes, viñetas, propaganda, correspondencia, bodegones, bolsas y similares, el segundo; una distribuidora como se desprende de su nombre y que en consecuencia, ambos nombres comerciales pueden ser usados para proteger establecimientos dedicados a actividades completamente diferentes. (...). Las empresas nicaragüenses deben competir lealmente utilizando nombres comerciales y marcas originales, y no tratando de imitar los nombre comerciales y marcas notorias, como el de su mandante para aprovecharse de su bien ganado prestigio, y en detrimento del consumidor que confundido adquirirá productos de inferior calidad, creyendo que son los que distribuye su mandante"212.

210 Sentencia 48, de las 10:45 a.m. del 22 de junio de 1994; consultada en formato digital elaborado por la Corte Suprema de Justicia.

211 Sentencia 34 de las 10:30 a.m. del 21 de marzo de 1996; consultada en formato digital elaborado por la Corte Suprema de Justicia.

212 "Artículo 3.- Signos que pueden constituir marca.

Las marcas podrán consistir, entre otros, en palabras o conjuntos de palabras, lemas y frases 


\section{Revista de ODerecho}

Como observamos, en la jurisprudencia nacional, se habla expresamente de semejanza de productos o bien se hace referencia a la clase para denotar similitud de productos, para indicar que por medio de la clase que protege los productos o servicios se puede producir asociación y por lo tanto, en nuestra opinión confusión.

\section{La plataforma legal en Nicaragua}

Las semejanzas o similitudes enunciadas en el apartado anterior es el baremo con el cual el sistema marcario mide la originalidad o novedad de una marca a fin de establecer efectivamente si entre marcas confrontadas se suscita un riesgo de confusión o asociación. En nuestra Ley de Marcas encontramos recogido en el artículo 3 de la Ley $380^{213}$, qué puede constituir una marca y de él obtenemos que nuestro sistema protege marcas denominativas, figurativas, mixtas, sonoras y olfativas; si bien las dos últimas categorías de marcas se encuentran incorporadas en la Ley, en la práctica no encontramos registradas marcas sonoras $\mathrm{u}$ olfativas; de lo recogido en la práctica nacional en cuanto a marcas se refiere y la semejanza que entre ellas se puedan suscitar se esgrimen tanto en oposiciones como en las contestaciones a las mismas, así como en los recursos de apelación las semejanzas que presentan las marcas confrontadas por parte del titular y aún cuando la doctrina establece como parámetro el no juzgar o invocar las diferencias, la parte pretensora del registro resalta la diferencia entre las marcas.

En la jurisprudencia nacional estas semejanzas quedan recogidas de manera breve sin conceptualizarlas, las que mejor quedan perfiladas son las semejanzas gráficas o visuales, ya que son las que más comúnmente se presentan; no obstante a nuestros tribunales les ha tocado conocer y fallar en casos que presentan "elaboración" para inducir al engaño a través de la confusión conceptual como quedó expuesto en el caso VAPO RUB v. VAPO II.

publicitarias, letras, cifras, monogramas, figuras, retratos, etiquetas, escudos, estampados, viñetas, orlas, lineas y franjas, y combinaciones y disposiciones de colores, sonidos y otros signos perceptibles tales como olores. Podrán asimismo consistir en la forma, presentación o acondicionamiento de los productos o de sus envases o envolturas, o de los medios o locales de expendio de los productos o servicios correspondientes."

213 Sobre la interpretación de la Ley el Código Civil de Nicaragua, parágrafo II, párrafo XVII. 
Revista de Derecho

\section{Ensayo de una postura al tenor de la interpretación doctrinal y literal de la norma}

\section{Replanteamiento del precepto}

Siendo que se suscita una contradicción, al menos en la aplicación de la norma, entre los artículos 26 inciso e), 8 inciso b), ambos de la Ley, y artículo 12 del Reglamento habrá que replantearse el alcance de cada uno, la jerarquía normativa, y el espíritu de su interpretación conforme posiciones doctrinales difundidas. Ha quedado dicho que en el cuerpo de Ley se guarda una visión amplia del principio de especialidad y en el cuerpo reglamentario una visión restringida.

La primera interrogante que salta a la vista es ¿̇el por qué se suscita esta dualidad interpretativa? En nuestra percepción el artículo 12 del Reglamento de la Ley establece unos límites y unos contornos a los derechos exclusivos, que dimanan de la condición de titular de la marca, que no los establece la Ley en ninguno de sus artículos, pero el exceso del artículo 12 no queda circunscrito a que se legisló por vía de Decreto donde el legislador de la ley no lo hizo; sino que su mayor limitante es que por querer acotar los derechos dominicales del titular de la marca, contradice, para violar, lo establecido en Ley, en la medida que al definir la propiedad de la marca reduce este derecho macro a la categoría de "clase". Estimamos, luego del estudio que se ha hecho, que en materia marcaria la definición de propiedad de marca no corresponde a un Reglamento sino que es materia toral y neurálgica de la Ley, en nuestro caso, el artículo 26 define los derechos de exclusiva, de forma que el Reglamento no debió volver sobre un concepto ya ofrecido y menos establecer unos contornos que permiten un marco de deambulación interpretativa y que esgrimen a su favor los terceros que quieren inscribir como suyas marcas idénticas o similares ya inscritas sobre la base de que estas marcas no fueron registradas para todos los productos dentro de la misma clase u otra.

Es así que conforme esta visión restringida y utilizando un ejemplo totalmente hipotético, quien tuviere registrado la marca océano para arroz no podrá impedir que un tercero quiera registrar océano para el producto sal, dentro de la misma clase. Lo que esgrime el tercero a su favor, y que genera la contradicción que hemos venido anotando en todo 
el trabajo, es la primera parte del artículo 12 “... La propiedad de una marca y el derecho a su uso exclusivo solo se adquiere con relación a los productos, mercancías o servicios para los que se hubiere solicitado y que estén comprendidos en una misma clase..."; sin embargo, la norma contiene una parte final que es neurálgica en su aplicación e interpretación “... sin perjuicio de lo establecido en el arto. 8 de la Ley”.

Esta parte final del artículo 12 nos orienta a replantearnos el asidero legal de la interpretación restringida que se ha pretendido hacer de este precepto. Las normas han de ser interpretadas en su literalidad y armónicamente ${ }^{214}$. Si bien la primera parte del artículo en comentario fija o ancla los derechos con una visión muy segmentada, a nuestro parecer, que deja el sabor de que el derecho nace y vive en sí mismo y solo para sí, aislándolo de su interrelación en sociedad, ofreciendo solo un ángulo de su panorama -- producto registrado para la clase - su parte final salva un error que pudo ser irreversible cuando remite a la aplicación del artículo 8 de la Ley. El legislador del Decreto especificó los derechos del titular - sobre sus productos registrados y dentro de su clase- para luego abrir el diapasón remitiendo al artículo 8 , cuya aplicación permitirá que ante supuestos de asociación o confusión el titular de la marca, aunque no tenga inscrito el producto dentro de su clase u otra, podrá oponerse a la inscripción del tercero, siempre que fundamente la similitud o identidad de la marca y el riesgo que ello le ocasiona en el mercado.

Por lo tanto estimamos que la parte final del artículo 12 salva la armonía interpretativa que debe primar en la aplicación de las normas, y en consecuencia no debe ser interpretado aisladamente del resto de la normativa sobre el tema, sino que en el espíritu de la hermenéutica de la totalidad, a cuyo tenor, y colacionando el ejemplo hipotético que líneas arriba referenciamos, no podrá pretender un tercero inscribir una marca idéntica para producto similar dentro de una misma clase, porque ello generaría un riesgo de confusión asociativa que excluye el artículo 8 inciso b, al que se llega por remisión del artículo 12.

2. Imbricación del principio de especialidad y el riesgo de confusión entre los signos confrontados

Nuestro ordenamiento jurídico se hizo eco de la imbricación del principio de especialidad y riesgo de asociación cuando permite en su

214 MARX, K. y ENGELS, F. Obras Completas T. XXIII. p. 188. 


\section{Revista de Derecho}

artículo 26 inciso e) y artículo 8 inciso b), al titular de una marca evitar que terceros registren marcas similares o idénticas para los mismos productos, productos similares o productos diferentes, pero que tengan una vinculación notoria o que los productos sean complementarios; en el plano de la práctica, este principio busca evitar subterfugios que conlleven a las siguientes situaciones:

a) El riesgo de confusión, principalmente; entendido como un "golpe de vista", casi de manera impulsiva y confiada lleva al consumidor a tomar otro producto o servicio, convencido que el que adquiere equivocadamente es el que realmente requiere; en un primer momento, este riesgo está dirigido principalmente a la existencia o inexistencia de semejanza o identidad en los signos y no toma en consideración otro aspecto que es la identidad o similitud de los productos para que se produzca la confusión; y

b) Elriesgodeasociación, queseasoma recientementeenlaslegislaciones y doctrina modernas; ya como un mecanismo más elaborado en la mente del adquirente de los bienes identificados por la marca; es así que se plantea que éste, conlleva un proceso mental que evoca en el recuerdo o en la experiencia del sujeto un contacto directo, un uso o el disfrute de un producto o servicio adquiridos previamente y que ha dejado una impresión positiva o agradable en el consumidor que le impele a adquirir nuevamente; pero de manera equívoca otro producto de la misma naturaleza bajo una marca idéntica o similar.

Siendo el principio de especialidad garante y expresión de los derechos de exclusiva de su titular, su principal cometido es evitar que se susciten riesgos de asociación o confusión en los productos, mercancías, o servicios que se ofertan en el mercado. Se trata entonces de figuras asociación - especialidad - que operan a la manera de ruedas dentadas que se concatenan y articulan en pos de un mismo fin: la protección de las creaciones del empresario y la salvaguarda de su derecho.

3. El triunfo de la tesis proteccionista a las creaciones intelectuales del empresario

Una interpretación doctrinal y sistemática de los artículos 8 inciso b), y 26 de la Ley y artículo 12 del Reglamento - este último con sus limitaciones y aciertos - permiten concluir que lo que se está protegiendo en ellos son las creaciones intelectuales del empresario y su esfuerzo por distinguir 
sus productos en el mercado, ese es el derecho supra que se protege mas allá de una clase u otra. Siempre que ese derecho se vea lacerado, por pretenderse la inscripción en la misma u otra clase de productos difundidos en el mercado, pues se estará vulnerando el derecho de propiedad marcaria, y ante ello el Derecho y el ordenamiento jurídico necesariamente reaccionará, porque la protección al derecho sobre las marcas vence las fronteras de "clases", para clamar protección en cualquier manifestación que se le vulnere, y esta posición doctrinalmente aceptada es justo el espíritu en el que ha de ser interpretada la norma, venciendo ritualismo de una literalidad restringida y descontextualizada como puede ser la errante interpretación que se ha pretendido, en nuestra práctica legal, para la primera parte del artículo 12.

Si hemos sostenido que el principio de especialidad tutela y constituye expresión de los derechos de exclusiva, y que se articula en función de evitar los riesgos de confusión o asociación, y estas resultan posiciones pacíficas en doctrina, no cabe otra postura al operador jurídico nicaragüense, que en materia de oposición de marcas, proteger al titular de la marca, cuando la inscripción de una posterior, idéntica o similar, le genere confusión en el mercado, porque con ello no hace más que acompasarse no sólo a un mandato normativo (arto. 8 inciso b), sino además a una posición doctrinal sedimentada.

Proteger las creaciones empresariales como componente propulsor de unas relaciones de mercado transparentes y leales, que abonan en pos de una libre pero leal competencia, constituye la columna vertebral del Derecho Marcario, en torno a lo cual deben nuclearse y ser interpretadas todas sus instituciones y categorías, a lo cual no escapa la inadmisibilidad de inscripción de una marca por lacerar derechos previamente adquiridos, y protegidos por la visión estructural del Derecho Marcario.

\section{Conclusiones}

1. Los artículos 8 inciso b) y 26 inciso e) de la Ley de Marcas nicaragüense y el artículo 12 del Reglamento de la Ley, constituyen expresión de un principio toral en materia marcaria que es el de especialidad, y a la vez consagran otra categoría de especial relieve que es el riesgo de confusión o asociación. No obstante en la práctica legal se han venido confrontando como contradictorios los artículos de la Ley con los del Reglamento. 


\section{Revista de ODerecho}

2. El análisis doctrinal del principio de especialidad permite calificar la regulación de los artículos 8 inciso b, y 26 inciso e), como amplia y redimensionada, en tanto califica como restrictiva y segmentaría la regulación del artículo 12 del Reglamento de la Ley.

3. Lainterpretación restrictiva del artículo 12 del Reglamento desprotege al titular de la marca, en la medida que conforme aquella visión podrá un tercero inscribir como suya marcas idénticas o similares de otro, que por no tenerlas inscritas para todos los productos dentro de la propia clase u otra, no podrá hacer valer su derecho por quedar éste circunscrito únicamente para los productos, mercancías o servicios que tenga inscrito.

4. No debe ser interpretado de forma segmentada el artículo 12 del Reglamento, reduciéndolo a su primera parte, porque la parte final del referido precepto “... sin perjuicio de lo establecido en el artículo 8 de la Ley.", salva la armonía interpretativa que debe primar en la aplicación de las normas, y en consecuencia no debe ser interpretado aisladamente del resto de la normativa sobre el tema, sino que en el espíritu de la hermenéutica de la totalidad, a cuyo tenor, no podrá pretender un tercero inscribir una marca idéntica para producto similar dentro de una misma clase, porque ello generaría un riesgo de confusión asociativa que excluye el artículo 8 inciso b, al que se llega por remisión del artículo 12.

5. De persistir en la práctica contradicciones en la interpretación entre los artículos de la Ley (artículo 8 inciso b), y artículo 26 inciso e), y el artículo 12 del Reglamento pues corresponderá prevaler los preceptos de la Ley por obedecer a una norma de mayor jerarquía.

6. El principio de especialidad no puede ser visto de forma restrictiva circunscrito como inherente a la clase o producto, el principio de especialidad a lo que va unido y es inherente es a la protección del derecho del titular de la marca, será especial en la medida que la titularidad de la marca otorga un derecho de exclusiva a su titular y conforme ese principio el titular defenderá erga omnes su derecho, sin que quepa invocar que el principio de especialidad restringe el derecho del titular a la manera de que no puede ser articulado para defenderse cuando un tercero pretende inscribir como suya un signo idéntico o similar ya inscrito, en el entendido de que la especialidad se circunscribe únicamente al producto registrado o a la clase para la cual fue otorgado el registro; y por tanto el titular debe tolerar que otro inscriba un signo suyo ya inscrito, aunque para otro producto. Se trata entonces de un principio que debe ser redimensionado 


\section{Revista de ODerecho}

conforme a la naturaleza del Derecho Marcario que consagra por sobre todo la protección al titular de la marca y en esa medida ha de ser visto y entendido.

7. El principio de especialidad en materia marcaria debe ser concebido en atención o en función de proteger la creación empresarial y el esfuerzo del empresario por distinguir sus productos en el mercado, ese ha de ser el real fundamento de la especialidad, que termina obviamente proyectándose en un producto, mercancía o servicio, pero se trata de un concepto supra o una visión supra al producto, mercancía o servicio concreto. Quiere esto decir que siempre que se ponga en riesgo la protección que merece el empresario por la identidad y singularidad de creaciones, indicará igualmente un riesgo o quiebre al principio de especialidad.

8. Siendo el principio de especialidad garante y expresión de los derechos de exclusiva de su titular, su principal cometido es evitar que se susciten riesgos de asociación o confusión en los productos, mercancías, o servicios que se ofertan en el mercado. Se trata entonces de figuras - asociación - especialidad - que operan a la manera de ruedas dentadas que se concatenan y articulan en pos de un mismo fin: la protección de las creaciones del empresario y la salvaguarda de su derecho.

9. Una interpretación doctrinal y sistemática de los artículos 8 inciso b), y 26 de la Ley y artículo 12 del Reglamento permiten concluir que lo que se está protegiendo en ellos son las creaciones intelectuales del empresario y su esfuerzo por distinguir sus productos en el mercado, ese es el derecho supra que se protege mas allá de una clase u otra. Siempre que ese derecho se vea lacerado, por pretenderse la inscripción en la misma u otra clase de productos difundidos en el mercado, pues se estará lacerando el derecho de propiedad marcaria, y ante ello el derecho y el ordenamiento jurídico necesariamente reaccionará, porque la protección al derecho sobre las marcas vence las fronteras de "clases", para clamar protección en cualquier manifestación que se le vulnere.

10. Proteger las creaciones empresariales como componente propulsor de unas relaciones de mercado transparentes y leales, que abonan en pos de una libre pero leal competencia, constituye la columna vertebral del Derecho Marcario, en torno a lo cual deben nuclearse y ser interpretadas todas sus instituciones y categorías, a lo cual no escapa la inadmisibilidad de inscripción de una marca por lacerar derechos previamente adquiridos, y protegidos por la visión estructural del Derecho Marcario. 


\section{Revisla de Derecho}

11. En cuanto a la novedad y distintividad de los signos deben atenderse los criterios establecidos por la doctrina sobre las semejanzas entre signos y los productos para valorar el grado de confusión o de asociación que se puede suscitar y que lleven al consumidor a error; debe haber una estimación del signo y de los productos o servicios, pues entre menos semejanzas haya entre dos signos y los productos o servicios pertenezcan a ramas de la industria lo más lejana una de la otra, menor riesgo de confusión o de asociación se producirá.

12. Esunaspectoaún en estudioquegenera extensasybienfundamentadas ponencias, las corrientes y opiniones de los estudiosos del tema y los fallos de los tribunales sobre el riesgo de asociación y de confusión; sin embargo en nuestra opinión el riesgo de confusión se puede suscitar sin incurrir en asociación; por el contrario, la asociación que se realice por la percepción de dos signos distintivos indubitablemente llevará al sujeto a confusión.

\section{Recomendaciones}

1. En cuanto al uso que se debe dar al principio de especialidad en nuestra realidad, consideramos que a fin de promover el ingenio y la creatividad de nuestros empresarios y las personas de quienes se auxilia en este campo de la propiedad intelectual se debe seguir la concepción amplia del principio de especialidad; además refuerza nuestra posición la ley, puesto que la concepción amplia de la especialidad de una marca está instituida en la Ley; el Reglamento interviene regulando aspectos que no le competen contradiciendo la Ley.

2. Crear espacios de debates entre los juristas del foro a fin de reflexionar desde posiciones doctrinales y ius positivistas, el alcance interpretativo de los artículos 8 inciso b) de la Ley, artículo 26 y artículo 12 del Reglamento.

3. En una futura reforma al Reglamento de la Ley de Marcas, Decreto No. 83 - 2001, recomendamos la supresión del artículo 12 en los términos en que actualmente está redactado por entender que crea espacios para una interpretación patológica que desvirtúa el principio de especialidad. 


\section{Revista de Derecho}

\section{Bibliografía}

\section{Textos}

BENDAÑA GUERRERO, Guy José, Curso de Derecho de Propiedad Industrial, ed. Hispamer, Managua, 1999.

BREUER MORENO, Pedro, Derecho de Marcas, 2da edición, Robis, Buenos Aires, 1946.

CUADRA ZAVALA, Joaquín, Anotaciones al Código Civil de Nicaragua, Ley No. 186 de febrero de 1904, ed. Hispamer, Bogotá, 2004.

FERNÁNDEZ-NÓVOA, Carlos, Tratado sobre Derecho de Marcas, $2^{\mathrm{a}}$ ed., Marcial Pons, Madrid, 2004.

LOBATO, Manuel, Comentario a la Ley 17/2001, de Marcas, Civitas, Madrid, 2002.

MARTÍNEZ MEDRANO, Gabriel/SOUCASSE, Gabriela, Derecho de Marcas, Ediciones La Roca, Buenos Aires, 2000.

OTAMENDI, Jorge, Derecho de Marcas, $4^{\mathrm{a}}$ ed., Lexis Nexos, Buenos Aires, 2002.

URÍA, Rodrigo/MENÉNDEZ, Aurelio, Curso de Derecho Mercantil, reimpresión, editorial CIVITAS, Madrid, 2001.

\section{Legislación}

Ley 380, Ley de Marcas y otros Signos Distintivos, publicada en La Gaceta, Diario Oficial número 70, del 16 de abril de 2001.

Ley 17/2001, Ley de Marcas, ed. Tecnos, Madrid, 2002.

Ley 580, Ley de Reformas y Adiciones a la Ley No. 380, Ley de Marcas y Otros Signos Distintivos, publicada en La Gaceta, Diario Oficial número 60, del 24 de marzo de 2006.

Reglamento de la Ley de marcas y otros signos distintivos, publicada en La Gaceta, Diario Oficial número 183, del 27 de septiembre de 2001. 
Revisla de Derecho

\section{Consulta en línea}

La Frontera entre Marcas Tridimensionales y Diseños Industriales. Monografías.com [en línea] 10 de noviembre 2008. http://www. monografias.com/trabajos $45 /$ marcas-tridimensionales/marcastridimensionales.shtml

Página OMPI, Clasificador Internacional de Niza, http://www.wipo.int/ classifications/nice/es/ [en línea] consultado 18 de noviembre 2008.

Protocolo para la Modificación al Convenio Centroamericano para la Protección de la Propiedad Industrial [en línea] consultado 31 de octubre de 2008. Disponible en World Wide Web: http://www. sica.int/centro_documentacion/inst/sgsica/Protocolo\%20de\%20 Modificaci\%C3\%B3n\%20al\%2oConvenio\%20Centroamericano\%20 para\%2ola\%2oProtecci\%C3\%B3n\%2ode\%2ola\%2oPropiedad\%2o Industrial\%20(Marcas\%20y\%20otros\%20signos\%2odistintivos).pdf.

RIOFRIO MARTINEZ VILLALBA, Juan Carlos, Artículos Doctrinales: Derecho Mercantil, Principios del Derecho de Marcas en la Comunidad Europea [en línea] http://noticias.juridicas.com/articulos/50Derecho\%20Mercantil/200305-45595410311241.html consultado 3 de noviembre 2008.

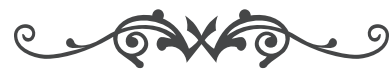

